\title{
Neuroprotective Role of Curcumin Against Benzo[a]pyrene-Induced Neurodegeneration in Zebrafish
}

\author{
Laxminandan Satpathy 1,* (D), Siba Prasad Parida 1 (i) \\ 1 Department of Zoology, School of Applied Sciences, Centurion University of Technology and Management, \\ Bhubaneswar, Odisha, 752050 India; laxminandansatpathy@gmail.com (L.S.); paridasp@gmail.com (S.P.P.); \\ * Correspondence: laxminandansatpathy@gmail.com (L.S.);
}

Received: 30.09.2021; Revised: 26.10.2021; Accepted: 29.10.2021; Published: 24.11.2021

\begin{abstract}
Curcuma longa L. has been shown to exhibit neuroprotection in the brain. Curcuma longa L. has been used for its neuroprotective effect in humans of neurological disorders. The present study is aimed to evaluate the neuroprotective role of curcumin, a key component of Curcuma longa L., following exposure to waterborne B[a]P. Wild-type adult zebrafish (Danio rerio) were assigned as naïve, control (dimethyl sulfoxide), curcumin, $\mathrm{B}[\mathrm{a}] \mathrm{P}$ (Benzo[a]pyrene) and $\mathrm{B}[\mathrm{a}] \mathrm{P}+$ curcumin group. $\mathrm{B}[\mathrm{a}] \mathrm{P}$-induced altered antioxidant levels were enhanced by curcumin in the $\mathrm{B}[\mathrm{a}] \mathrm{P}+$ curcumin group. Findings showed that $\mathrm{B}[\mathrm{a}] \mathrm{P}$ induced anti-anxiety behavioral response and altered antioxidant activity in zebrafish is reduced by curcumin. The periventricular grey zone (PGZ) located on the optic tectum $(\mathrm{TeO})$ in the zebrafish brain regulates anxiety-like behavior. Our histological study showed a significant increase in pyknotic neuronal counts in $\mathrm{PGZ}$ of $\mathrm{TeO}$ in adult zebrafish brain following $\mathrm{B}$ [a]P exposure and was improved by curcumin co-supplementation. Recent findings showed that curcumin improves glutathione production, an antioxidant necessary for maintaining redox homeostasis and shows a neuroprotective role in brain cells. The present study's findings address the potential role of curcumin co-supplementation as a herbal therapeutic against B[a]P-induced neurotoxicity in zebrafish.
\end{abstract}

Keywords: curcumin; zebrafish; benzo[a]pyrene; oxidative stress; neurodegeneration; neuroprotection (C) 2021 by the authors. This article is an open-access article distributed under the terms and conditions of the Creative Commons Attribution (CC BY) license (https://creativecommons.org/licenses/by/4.0/).

\section{Introduction}

Environmental pollutants are a major threat to living systems. Aquatic ecosystem polluted with polycyclic aromatic hydrocarbons (PAHs) produced by incomplete combustion of organic materials [1,2]. Benzo[a]pyrene is a colorless polycyclic aromatic hydrocarbon known for its carcinogenicity [3]. Exposure of B[a]P causes neurodegeneration and directly acts on the brain [4]. It causes oxidative stress and induces neurobehavioral changes in aquatic organisms $[5,6]$. B[a]P easily pollutes groundwater and nearby waterways, polluting the aquatic environment [7].

Recently, the neurotoxic potential of $\mathrm{B}[\mathrm{a}] \mathrm{P}$ causing behavioral alterations and oxidative stress in zebrafish has been reported [5,6]. As the aquatic environment provides a sink for environmental pollutants like B[a]P, studies need to be conducted on the fish model to explain the effect of $\mathrm{B}[\mathrm{a}] \mathrm{P}$ on oxidative stress-induced neurodegeneration and anxiety-like behavioral response in aquatic animals [6,8]. B [a]P plays a crucial role in mechanical aspects of oxidative damage to lipid membranes, nucleic acids, and proteins and change in antioxidant status.

The oxidative stressors in the fish model have been found to be similar to the mammal model because zebrafish (Danio rerio) possesses all major neuro mediators systems and 
approximately $70 \%$ of human genes have at least one zebrafish orthologue, suggesting zebrafish to be an ideal animal model for oxidative stress caused by B[a]P [6, 9-13]. Zebrafish nervous system performs complex functions that are similarly modulated by neurotransmitter molecules in mammals. Zebrafish is an ideal experimental model of the aquatic habitat to study the effect of xenobiotics, neurodegeneration, and behavioral response [6, 14, 15]. Zebrafish possess all vital antioxidant enzymes [16]. It exhibits the same defense mechanism against toxic xenobiotics as mammals, including the body's responses to oxidative stress and defense against toxic and xenobiotic metabolism. Zebrafish behavior on acute exposure to B[a]P has been well studied $[6,15]$. Previous findings addressed the scototaxis behavior as a measure of anxiety-like character in zebrafish [6,17-19]. Very little research work addresses the effect of $\mathrm{B}[\mathrm{a}] \mathrm{P}$ on histological parameters of zebrafish as the brain cells are vulnerable to oxidative stress leading to several neurodegenerative diseases in the animals [20]. B[a]P-induced oxidative damage on the brain has been reported by several researchers in different animal models [21]. B[a]P undergoes catabolism inside the body of the living organism into a more potent neurotoxic compound and thus resulting in increased oxidative damage by the generation of reactive oxygen species (ROS) [22,23]. Therefore, therapeutic approaches need to be developed to counteract the hazardous effect of $\mathrm{B}[\mathrm{a}] \mathrm{P}$ on the brain.

Curcuma longa L., also known as turmeric, is used as an important herb in Ayurveda and Siddha medicine to treat several neurodegenerative diseases $[6,13]$. Some phytochemicals from turmeric exhibit a significant neuroprotective role in various experimental animal models of neurological disorders [24]. Preclinical trials support the neuroprotective role of turmeric against anxiety disorder, oxidative stress-induced neurodegeneration $[25,26]$. Study shows that Curcuma longa L. can reduce symptoms of anxiety [27,28]. The mechanism of its neuroprotective role is not completely understood. However, Curcuma longa L. has been assumed to act mainly through its antioxidant and anti-inflammatory properties. It is a potent inhibitor of reactive oxygen species (ROS) [29,30]. It also regulates several neurotransmitter levels in the brain. It can normalize specific physiological processes. The antioxidant properties of curcumin are mainly achieved by regulating the brain oxidative damage markers such as glutathione (GSH) and lipid peroxidation.

Our main objective to use the zebrafish model is to address the possible outcomes of increasing contaminants such as $\mathrm{B}[\mathrm{a}] \mathrm{P}$ in aquatic habitats. Increasing pollution in the aquatic system has a direct effect on humans and aquatic life. We have taken zebrafish as our animal model as it has significant genomic similarities with humans and has similar cellular responses to oxidative damage. Therefore, a regulated dose of curcumin provides neuroprotection against $\mathrm{B}[\mathrm{a}] \mathrm{P}$-induced oxidative stress. Thus, the present study was performed on zebrafish to examine the potential neuroprotective role of co-supplementation of curcumin against $\mathrm{B}$ [a]P-induced neurodegeneration.

\section{Materials and Methods}

The imperative chemicals and standard reagents used in the experiments were purchased from Sigma-Aldrich unless otherwise mentioned.

\subsection{Experimental animals.}

Adult zebrafish (short-fin, 6-8 month-old, $3-4 \mathrm{~cm}$ in length, $~ 50: 50$ male: female ratio and weigh about $1.0 \pm 0.78 \mathrm{~g}$ ) were collected from ornamental fish hatchery of the Central 
Institute of Freshwater Aquaculture (CIFA), Odisha, India, and were maintained in a 50-L aquarium at room temperature. Tanks were filled with filtered water, and the $\mathrm{pH}$ of the system water was maintained at 7.5. The salinity and hardness of water were maintained at $0.1 \mathrm{ppt}$ and $100 \mathrm{mg} / \mathrm{L} \mathrm{CaCO}_{3}$, respectively [6]. They were left for acclimatization for 9 days (48 hours settling-in) and fed twice per diem with commercial fish food collected from a local market. Illumination was provided by ceiling-mounted light tubes on a 14:10 h (day: night) cycle. Hundred zebrafish were assigned into five experimental groups viz. naïve, control (vehicletreated, i.e., dimethyl sulfoxide (DMSO)), B[a]P, curcumin, and $\mathrm{B}[\mathrm{a}] \mathrm{P}+$ curcumin and maintained in 1-L capacity rectangular aerated glass containers.

\subsubsection{Dose standardization of $\mathrm{B}[\mathrm{a}] \mathrm{P}$.}

Waterborne acute toxicity test for $\mathrm{B}[\mathrm{a}] \mathrm{P}$ and dose standardization $\left(0.4 \mu \mathrm{g} \mathrm{mL}^{-1}\right)$ has already been reported. The neurobehavioral response in adult zebrafish abruptly changed at 1.6 $\mathrm{mg} / \mathrm{L}$ of B[a]P [31]. Therefore, we have chosen a concentration of $0.4 \mu \mathrm{g} \mathrm{mL}^{-1}$ for $\mathrm{B}[\mathrm{a}] \mathrm{P}$ exposure to adult zebrafish for 7 days.

\subsubsection{Dose standardization of curcumin.}

Waterborne acute toxicity test for curcumin and dose standardization has already been reported using a dose-response curve [13]. Median lethal concentration ( $\mathrm{LC}_{50}$ ) was 173.516 $\mu \mathrm{M}$ (63.91 $\mathrm{mg} \mathrm{L}^{-1}$ ) [13]. Therefore, we have chosen a much lower concentration was chosen for neurobehavioral assessment, same as $\mathrm{B}$ [a]P concentration. Curcumin was supplemented at a concentration of $0.4 \mu \mathrm{g} \mathrm{mL} \mathrm{m}^{-1}$ for waterborne administration for 7 days.

\subsection{Neurobehavioral tests.}

\subsubsection{Light and dark box test.}

Light and dark box test (LDBT) is used to quantify the scototaxic behavior. Zebrafish exhibit a marked preference for dark environments. It has already been reported that $\mathrm{B}[\mathrm{a}] \mathrm{P}-$ treated group spent more time in the light compartment as compared with naïve, control (vehicle-treated DMSO), curcumin, and $\mathrm{B}[\mathrm{a}] \mathrm{P}+$ curcumin, and the number of entries to the dark compartment was significantly increased in the $\mathrm{B}[\mathrm{a}] \mathrm{P}+$ curcumin-co-supplemented group as compared to $\mathrm{B}[\mathrm{a}] \mathrm{P}$ treated groups [6].

\subsubsection{Novel tank diving test.}

A novel tank diving test (NTDT) is also used to quantify anxiety-like behavior. It has already been reported that $\mathrm{B}[\mathrm{a}] \mathrm{P}$-treated groups spent more time in the top zone of the diving tank compared with naïve, control (vehicle-treated DMSO), curcumin, and $\mathrm{B}[\mathrm{a}] \mathrm{P}+$ curcumin. Contrarily, B[a]P + curcumin co-supplemented group spent significant time in the bottom zone, and latency to enter the top zone was significantly decreased in $\mathrm{B}[\mathrm{a}] \mathrm{P}$ treated group as compared to curcumin and $\mathrm{B}[\mathrm{a}] \mathrm{P}+$ curcumin co-supplemented groups [6].2.4. Biochemical test.

On completion of the time period of $\mathrm{B}[\mathrm{a}] \mathrm{P}+$ curcumin co-supplementation, zebrafishes were sacrificed, and the brains were removed over ice trays. Tissue homogenate was prepared in a ratio of $1 \mathrm{~g}$ of wet tissue to 10 times ice-cold $50 \mathrm{mM}$ phosphate buffer saline and processed in Tris- $\mathrm{HCl}$ buffer at $\mathrm{pH} 7.4$ to prepare $10 \%$ tissue homogenate as the protocol suggested 
previously $[32,33]$. The homogenate was used for the estimation of oxidative stress markers and antioxidant activity. $100 \mu \mathrm{L}$ of homogenate was used to estimate thiobarbituric acid reactive substance (TBARS) $[34,35]$. The remaining part of the homogenate was mixed with an equal volume of phosphoric acid $(200 \mu \mathrm{L})$, centrifuged at $4000 \mathrm{xg}\left(4^{\circ} \mathrm{C}\right.$, for $\left.15 \mathrm{~min}\right)$ and the supernatant was incubated with 5, 5' -dithiobis (2- nitrobenzoic acid) and used for GSH assay [36-38].

\subsubsection{Estimation of lipid peroxidation.}

Lipid peroxidation was measured by observing the formation of thiobarbituric acid reactive substance (TBARS) as per the protocol suggested previously [34]. Briefly, to $100 \mu \mathrm{L}$ of the sample, an aliquot of brain homogenate, a $3.8 \mathrm{~mL}$ thiobarbituric acid reagent, was added and heated in a water bath at $95{ }^{\circ} \mathrm{C}$ for $60 \mathrm{~min}$ and centrifuged at $12000 \mathrm{xg}$ for $10 \mathrm{~min}$. The pink chromogen formed was measured in a spectrophotometer at $532 \mathrm{~nm}$. TBARS concentration was calculated from its molar extinction coefficient at $1.56 \times 10^{5} \mathrm{M}^{-1} \mathrm{~cm}^{-1}$, and the results were expressed as nanomoles of TBARS formed per milligram of protein.

\subsubsection{Estimation of glutathione (GSH).}

The GSH in brain tissue homogenate was measured as per the procedure suggested previously [36-38]. Briefly, $200 \mu \mathrm{L}$ of the homogenate was mixed with an equal volume of phosphoric acid $\left(\mathrm{H}_{3} \mathrm{PO}_{4}\right)$ and subsequently centrifuged at $4000 \mathrm{xg}$ for $15 \mathrm{~min}$ at $4{ }^{\circ} \mathrm{C}$. The supernatants were used for estimation of GSH by 30 min incubation with Ellman's reagent. Readings were taken at $412 \mathrm{~nm}$ using a spectrophotometer. The amount of GSH was calculated using a standard curve and expressed in micromoles per gram of tissue.

2.5. Histopathological study by hematoxylin and eosin staining (HES).

Hematoxylin and eosin staining was conducted as per the protocol suggested previously [5]. The whole-brain of zebrafish was collected and isolated at $4{ }^{\circ} \mathrm{C}$ followed by the addition of $30 \%$ sucrose solution after the completion of the experimental period of exposure. Then serial cryosectioning of $10 \mu \mathrm{m}$ thickness was carried out, and HES was done for histopathological studies. The sections were observed under a bright-field microscope, and images of brain sections were taken with 100x magnification (Olympus BX43, Japan made). Neurons showing staining patterns of pyknosis were counted using stereo investigator software (MBF Bioscience, USA). The obtained results were expressed as a percent of control, considering the control value as $100 \%$.

\subsection{Statistical analysis.}

All data were presented as mean \pm SEM. Results were compared using one-way ANOVA analysis of variance followed by Newman-Keuls post-hoc test for comparisons between naïve, control, curcumin, and $\mathrm{B}[\mathrm{a}] \mathrm{P}+$ curcumin groups. In all the groups, the significance level was considered to be $p<0.05$. 


\section{Results and Discussion}

\subsection{Biochemical assay.}

The exposure to benzo[a]pyrene $(\mathrm{B}[\mathrm{a}] \mathrm{P})$ for 7 days significantly increased lipid peroxidation as compared with the naïve and control group (Figure $1 \mathrm{~A}$ ). The $\mathrm{B}[\mathrm{a}] \mathrm{P}+$ curcumin co-supplemented group showed a significant reduction in lipid peroxidation as compared with $\mathrm{B}[\mathrm{a}] \mathrm{P}$ treated group (Figure 1A). GSH levels also significantly decreased following B[a]P exposure compared with the naïve, control group, and $\mathrm{KH}$ groups. Supplementation of curcumin in the $\mathrm{B}[\mathrm{a}] \mathrm{P}+$ curcumin group significantly increased the GSH level when compared with $\mathrm{B}[\mathrm{a}] \mathrm{P}$ (Figure 2A).

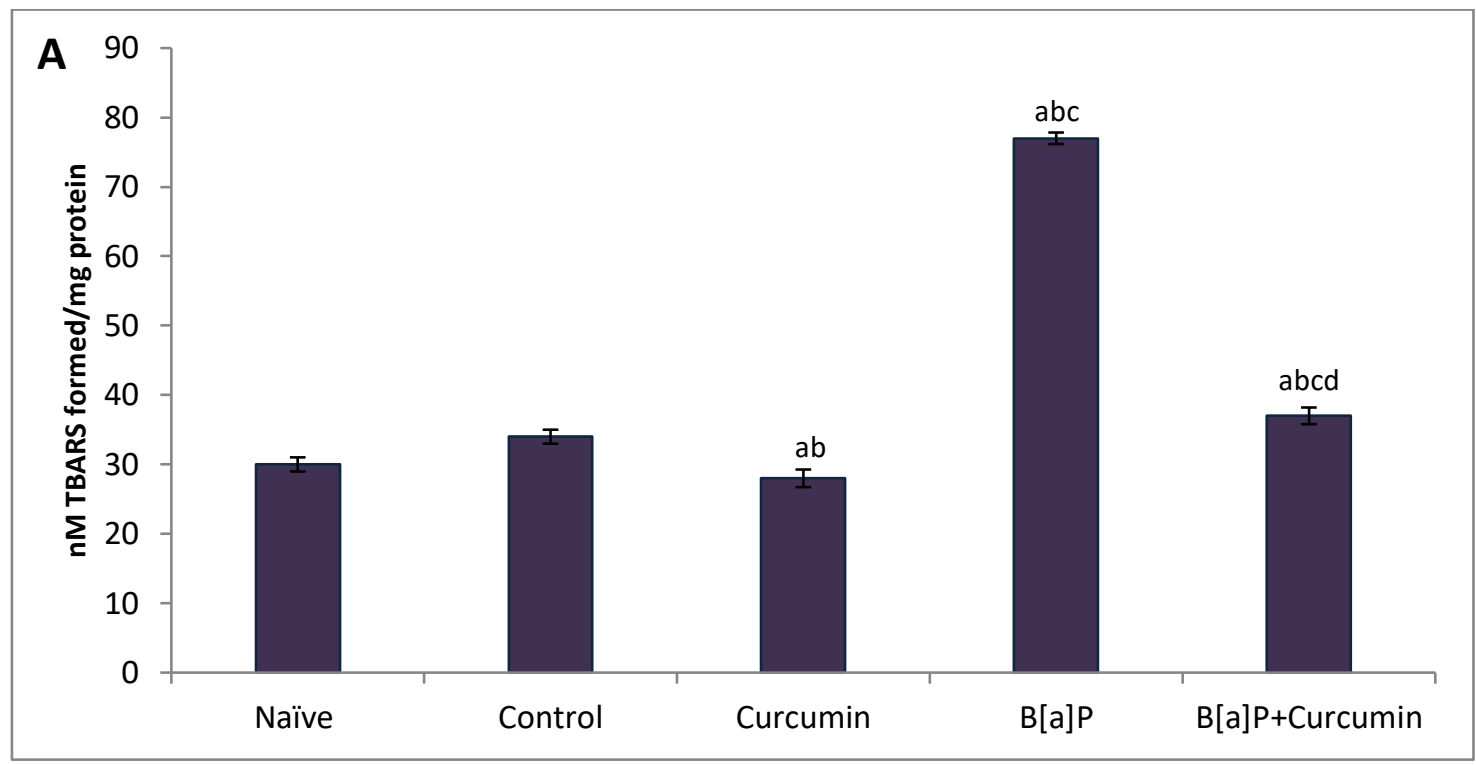

Figure 1. Lipid peroxidation. Graph showing a significant increase in lipid peroxidation (nmol TBARS formed $\mathrm{mg}^{-1}$ of protein) (A) in the whole brain of zebrafish following $\mathrm{B}$ [a]P exposure for a period of 7 days. Curcumin supplementation in $\mathrm{B}$ [a]P-treated groups significantly decreased lipid peroxidation. Values are expressed as mean \pm SEM. ${ }^{\mathrm{a}} p<0.05$ when compared with the naïve group; ${ }^{\mathrm{b}} p<0.05$ when compared with the control group;

${ }^{\mathrm{c}} p<0.05$ when compared with the curcumin group and ${ }^{\mathrm{d}} p<0.05$ when compared with the B[a]P group.

\subsection{Histopathological study hematoxylin and eosin staining (HES).}

Hematoxylin and eosin staining of the periventricular grey zone (PGZ) of the optic tectum $(\mathrm{TeO})$ in the zebrafish brain's section showed a significant increase in pyknotic neuronal counts in $\mathrm{B}[\mathrm{a}] \mathrm{P}$-exposed group as compared with the naïve and control groups (Figure 3A). However, curcumin co-supplementation significantly decreases the pyknotic cell count in $\mathrm{B}[\mathrm{a}] \mathrm{P}+$ curcumin groups as compared with $\mathrm{B}[\mathrm{a}] \mathrm{P}$ groups (Figure $3 \mathrm{~A}$ ). Further observations showed that waterborne $\mathrm{B}[\mathrm{a}] \mathrm{P}$ exposure significantly increases pyknotic neuronal counts in PGZ region, whereas curcumin co-supplementation leads to a reduction in pyknosis, suggesting the neuroprotective efficacy of curcumin (Figure 3B).

The present experiment was conducted on zebrafish to explain B[a]P-induced neurodegeneration, and to prevent these effects, a standardized dose of curcumin was used as a neuroprotectant. Thus, our present study was intended to address the neurotoxic effect of $\mathrm{B}[\mathrm{a}] \mathrm{P}$, and as a therapeutic measure, we have considered co-supplementation of curcumin in an aquatic environment using zebrafish. 


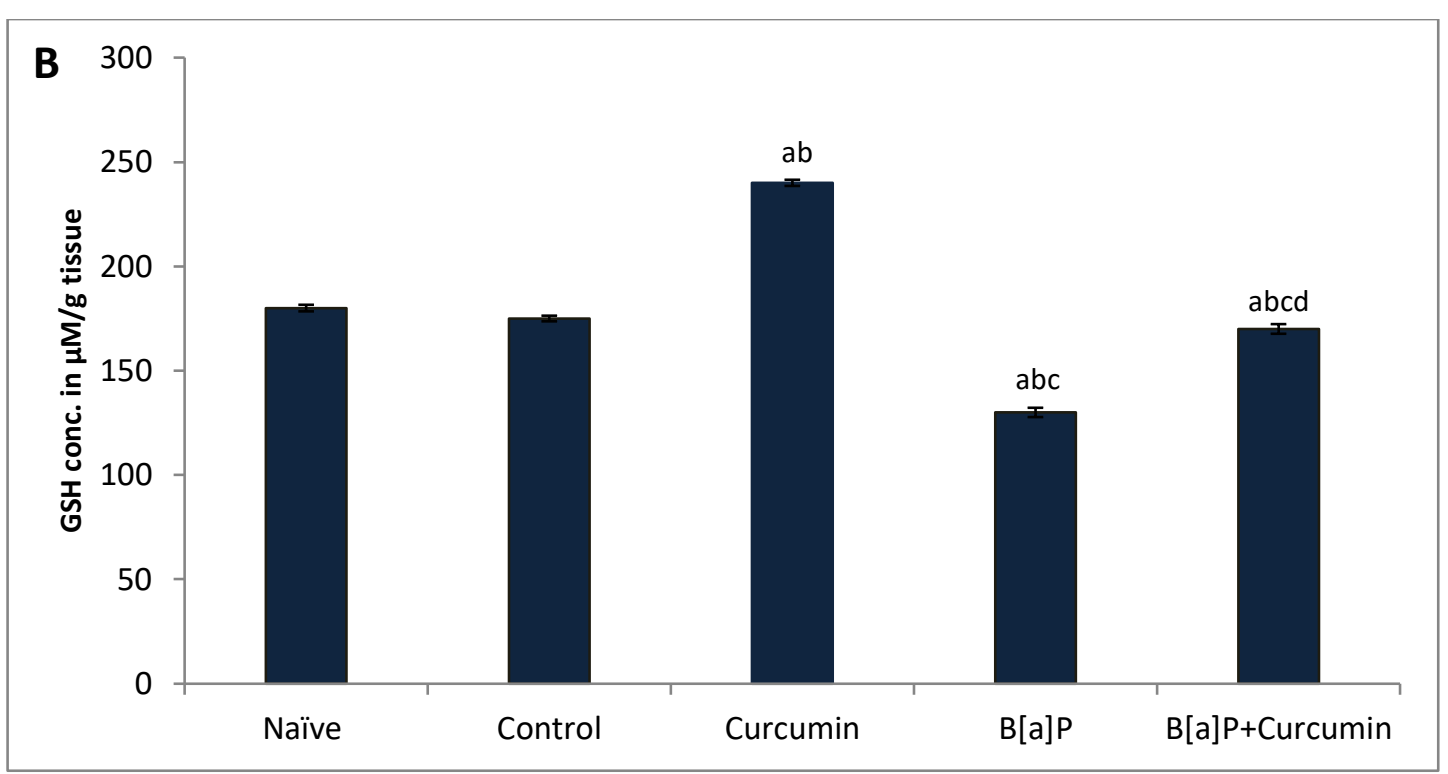

Figure 2. Biochemical assay of GSH level. Graphs show a significant decrease in the concentration of GSH ( $\mu \mathrm{M} \mathrm{g}^{-1}$ of protein) (A) in the whole brain of zebrafish following B[a]P exposure for 7 days. Curcumin supplementation significantly increased the antioxidant activity. Values are expressed as mean \pm SEM. ${ }^{a} p<0.05$ when compared with the naïve group; ${ }^{b} p<0.05$ when compared with the control group; ${ }^{c} p<0.05$ when compared with the curcumin group and ${ }^{\mathrm{d}} p<0.05$ when compared with the $\mathrm{B}[\mathrm{a}] \mathrm{P}$ group.
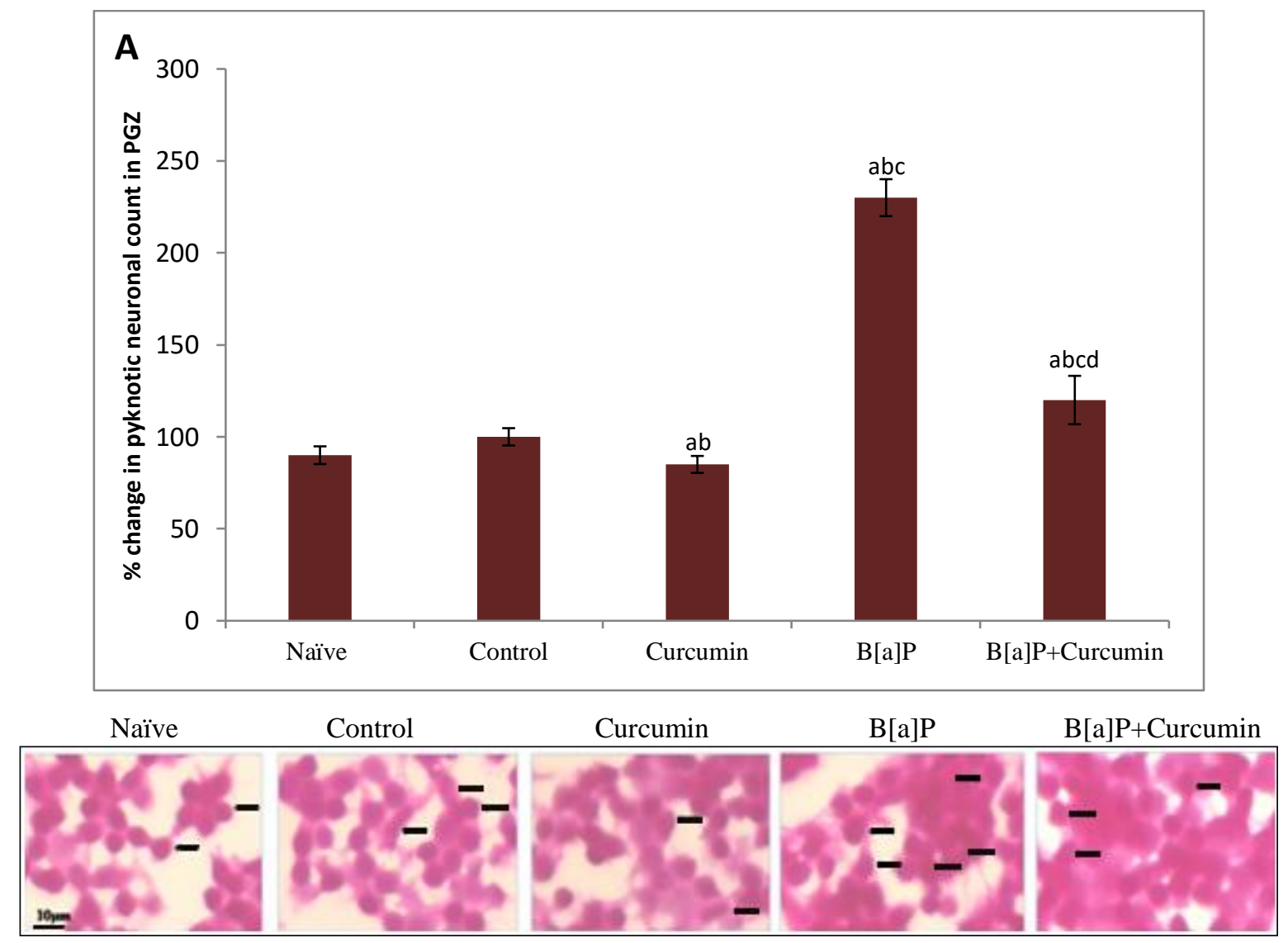

Figure 3. Neuropathological study by hematoxylin and eosin staining. Graph showing significant changes in the number of pyknotic cells in the PGZ region of TeO of zebrafish brain (A) following waterborne supplementation of $\mathrm{B}[\mathrm{a}] \mathrm{P}$ and curcumin for 7 days. Representative images of a cross-sectional view of zebrafish brain following hematoxylin and eosin staining (B). Arrowheads represent pyknotic neuronal cells in the PGZ region of $\mathrm{TeO}(\mathrm{B})$. Magnification and scale bar 100x correspond to $10 \mu \mathrm{m}$ of different experimental groups.

Values are expressed as mean \pm SEM. ${ }^{\mathrm{a}} p<0.05$ when compared with the naïve group; ${ }^{\mathrm{b}} p<0.05$ when compared with the control group; ${ }^{c} p<0.05$ when compared with curcumin group and ${ }^{\mathrm{d}} p<0.05$ when compared with the

$$
\mathrm{B}[\mathrm{a}] \mathrm{P} \text { group. }
$$


A dose for $\mathrm{B}[\mathrm{a}] \mathrm{P}$ for waterborne exposure was chosen $(0.4 \mu \mathrm{L}$ per $\mathrm{mL})$ based on a concentration in the aquatic environment. The dose of curcumin chosen for the present study is $0.4 \mu \mathrm{L}$ per $\mathrm{mL}$ of water which is much lower than the doses that have caused teratogenic effects and embryotoxicity in zebrafish embryos [13, 39-41]. $\mathrm{B}$ [a]P has a direct impact on the brain antioxidant defense system and antioxidant activity. Curcumin has neuroprotective role [42]. Curcumin is a powerful anti-aging, anti-anxiety, anti-cancer, anti-inflammatory, and antiviral compound [43-57]. We assumed that curcumin co-supplementation could restore B[a]Pinduced oxidative stress in zebrafish.

\section{Conclusions}

The present study demonstrated that a standard dose of curcumin co-supplementation improves the adverse effect of $\mathrm{B}[\mathrm{a}] \mathrm{P}$. From the above findings, it is evident that curcumin is capable of protecting the brain against $\mathrm{B}[\mathrm{a}] \mathrm{P}$-induced oxidative stress leading to neurodegeneration by maintaining the concentrations of antioxidants. The present study elucidated the role of curcumin as a neuroprotective agent against $\mathrm{B}[\mathrm{a}] \mathrm{P}$-induced biochemical and pathological alternations in the zebrafish brain.

\section{Funding}

This research received no external funding.

\section{Acknowledgments}

This research has no acknowledgment.

\section{Conflicts of Interest}

The authors declare no conflict of interest.

\section{References}

1. Maliszewska-Kordybach, B. Sources, Concentrations, Fate and Effects of Polycyclic Aromatic Hydrocarbons (PAHs) in the Environment. Part A: PAHs in Air. Polish Journal of Environmental Studies 1999, 8, 131-136.

2. Abdel-Shafy, H. I.; Mansour, M. S. A review on polycyclic aromatic hydrocarbons: source, environmental impact, effect on human health and remediation. Egyptian journal of petroleum 2016, 25, 107-123, https://doi.org/10.1016/j.ejpe.2015.03.011.

3. Cheng, S.-q.; Xia, Y.-y.; He, J.-1.; Liu, X.-q.; Chen, X.-m.; Ding, Y.-b.; Wang, Y.-X.; Peng, B.; Tu, B.-j. Neurotoxic effect of subacute benzo(a)pyrene exposure on gene and protein expression in Sprague-Dawley rats. Environmental Toxicology and Pharmacology 2013, 36, 648-658, https://doi.org/10.1016/j.etap.2013.06.008.

4. Cherif, L. S.; Cao-Lei, L.; Farinelle, S.; Muller, C. P.; Turner, J. D.; Schroeder, H.; Grova, N. Assessment of 9-OH- and 7, 8-diol-benzo [a] pyrene in Blood as Potent Markers of Cognitive Impairment Related to benzo [a] pyrene Exposure: An Animal Model Study. Toxics 2021, 9, 50, https://doi.org/10.3390/toxics9030050.

5. Mohanty, R.; Das, S. K.; Patri, M. Modulation of benzo [a] pyrene induced anxiolytic-like behavior by retinoic acid in zebrafish: involvement of oxidative stress and antioxidant defense system. Neurotoxicity research 2017, 31, 493-504, https://doi.org/10.1007/s12640-016-9694-5.

6. Satpathy, L.; Parida, S. P. Study on the Effects of Kandhamal Haladi in Benzo [a] Pyrene-Induced Behavioral Changes in Adult Zebrafish (Danio rerio). Polycyclic Aromatic Compounds 2021, 1-8, https://doi.org/10.1080/10406638.2021.1886124.

7. Guo, W.; He, M.; Yang, Z.; Lin, C.; Quan, X.; Wang, H. Distribution of polycyclic aromatic hydrocarbons in water, suspended particulate matter and sediment from Daliao River watershed, China. Chemosphere 2007, 68, 93-104, https://doi.org/10.1016/j.chemosphere.2006.12.072. 
8. Billiard, S. M.; Timme-Laragy, A. R.; Wassenberg, D. M.; Cockman, C.; Di Giulio, R. T. The role of the aryl hydrocarbon receptor pathway in mediating synergistic developmental toxicity of polycyclic aromatic hydrocarbons to zebrafish. Toxicological Sciences 2006, 92, 526-536, https://doi.org/10.1093/toxsci/kfl011.

9. Kelly, K. A.; Havrilla, C. M.; Brady, T. C.; Abramo, K. H.; Levin, E. D. Oxidative stress in toxicology: established mammalian and emerging piscine model systems. Environmental health perspectives 1998, 106, 375-384, https://doi.org/10.1289/ehp.98106375.

10. Winston, G.W. Oxidants and antioxidants in aquatic animals. Comparative Biochemistry and Physiology Part C: Comparative Pharmacology 1991, 100, 173-176, https://doi.org/10.1016/0742-8413(91)90148-M.

11. Howe, K.; Clark, M. D.; Torroja, C. F.; Torrance, J.; Berthelot, C.; Muffato, M.; Teucke, M. The zebrafish reference genome sequence and its relationship to the human genome. Nature 2013, 496, 498-503, https://doi.org/10.1038/nature12111.

12. Kalueff, A. V.; Stewart, A. M.; Gerlai, R. Zebrafish as an emerging model for studying complex brain disorders. Trends in pharmacological sciences 2014, 35, 63-75, https://doi.org/10.1016/j.tips.2013.12.002.

13. Satpathy, L.; Parida, S. P. Acute Toxicity Assessment and Behavioral Responses Induced by Kandhamal Haladi in Adult Zebrafish (Danio rerio). Biointerface Research in Applied Chemistry 2020, 11, 7368-81, https://doi.org/10.33263/BRIAC111.73687381.

14. Bault, Z. A.; Peterson, S. M.; Freeman, J. L. Directional and color preference in adult zebrafish: Implications in behavioral and learning assays in neurotoxicology studies. Journal of Applied Toxicology 2015, 35, 15021510, https://doi.org/10.1002/jat.3169.

15. Gao, D.; Wu, M.; Wang, C.; Wang, Y.; Zuo, Z. Chronic exposure to low benzo [a] pyrene level causes neurodegenerative disease-like syndromes in zebrafish (Danio rerio). Aquatic toxicology 2015, 167, 200-208, https://doi.org/10.1016/j.aquatox.2015.08.01.

16. Hsu, C. H.; Wen, Z. H.; Lin, C. S.; Chakraborty, C. The zebrafish model: use in studying cellular mechanisms for a spectrum of clinical disease entities. Current neurovascular research 2007, 4, 111-120, https://doi.org/10.2174/156720207780637234.

17. Bencan, Z.; Sledge, D.; Levin, E. D. Buspirone, chlordiazepoxide and diazepam effects in a zebrafish model of anxiety. Pharmacology Biochemistry and Behavior 2009,94, 75-80, https://doi.org/10.1016/j.pbb.2009.07.009.

18. Grossman, L.; Utterback, E.; Stewart, A.; Gaikwad, S.; Chung, K. M.; Suciu, C.; Kalueff, A. V. Characterization of behavioral and endocrine effects of LSD on zebrafish. Behavioural brain research 2010, 214, 277-284, https://doi.org/10.1016/j.bbr.2010.05.039.

19. Maximino, C.; de Brito, T. M.; da Silva Batista, A. W.; Herculano, A. M.; Morato, S.; Gouveia Jr, A. Measuring anxiety in zebrafish: a critical review. Behavioural brain research 2010, 214, 157-171, https://doi.org/10.1016/j.bbr.2010.05.031.

20. Bouayed, J.; Rammal, H.; Soulimani, R. Oxidative stress and anxiety: relationship and cellular pathways. Oxidative medicine and cellular longevity 2009, 2, 63-67, https://doi.org/10.4161/oxim.2.2.7944.

21. Zhang, M. A.; Chen, F. H.; Huang, Z. Y.; Zhang, X. C. Elaidic acid enhanced the simultaneous neurotoxicity attributable to the cerebral pathological lesion resulted from oxidative damages induced by acrylamide and benzo (a) pyrene. Toxicology and industrial health 2011,27, 661-672, https://doi.org/10.1177\%2F0748233710393399.

22. Jiang, W.; Welty, S. E.; Couroucli, X. I.; Barrios, R.; Kondraganti, S. R.; Muthiah, K.; Moorthy, B. Disruption of the Ah receptor gene alters the susceptibility of mice to oxygen-mediated regulation of pulmonary and hepatic cytochromes P4501A expression and exacerbates hyperoxic lung injury. Journal of Pharmacology and Experimental Therapeutics 2004, 310, 512-519, https://doi.org/10.1124/jpet.103.059766.

23. Arzuaga, X.; Wassenberg, D.; Di Giulio, R.; Elskus, A. The chlorinated AHR ligand 3, 3', 4, 4', 5pentachlorobiphenyl (PCB126) promotes reactive oxygen species (ROS) production during embryonic development in the killifish (Fundulus heteroclitus). Aquatic toxicology 2006, 76, 13-23, https://doi.org/10.1016/j.aquatox.2005.07.013.

24. Kumar, G. P.; Khanum, F. Neuroprotective potential of phytochemicals. Pharmacognosy reviews 2012, 6 , 81, https://dx.doi.org/10.4103\%2F0973-7847.99898.

25. Kaufmann, F. N.; Gazal, M.; Bastos, C. R.; Kaster, M. P.; Ghisleni, G. Curcumin in depressive disorders: an overview of potential mechanisms, preclinical and clinical findings. European journal of pharmacology 2016, 784, 192-198, https://doi.org/10.1016/j.ejphar.2016.05.026.

26. Nam, S. M.; Choi, J. H.; Yoo, D. Y.; Kim, W.; Jung, H. Y.; Kim, J. W.; Hwang, I. K. Effects of curcumin (Curcuma longa) on learning and spatial memory as well as cell proliferation and neuroblast differentiation 
in adult and aged mice by upregulating brain-derived neurotrophic factor and CREB signaling. Journal of medicinal food 2014, 17, 641-649, https://doi.org/10.1089/jmf.2013.2965.

27. Esmaily, H.; Sahebkar, A.; Iranshahi, M.; Ganjali, S.; Mohammadi, A.; Ferns, G.; Ghayour-Mobarhan, M. An investigation of the effects of curcumin on anxiety and depression in obese individuals: A randomized controlled trial. Chinese journal of integrative medicine 2015, 21, 332-338, https://doi.org/10.1007/s11655015-2160-z.

28. Hewlings, S. J.; Kalman, D. S. Curcumin: a review of its effects on human health. Foods 2017, 6, 92, https://dx.doi.org/10.3390\%2Ffoods6100092.

29. Calabrese, V.; Bates, T. E.; Mancuso, C.; Cornelius, C.; Ventimiglia, B.; Cambria, M. T.; Dinkova-Kostova, A. T. Curcumin and the cellular stress response in free radical-related diseases. Molecular nutrition \& food research 2008, 52, 1062-1073, https://dx.doi.org/10.1089\%2Fars.2009.3074.

30. Mohammadi, A.; Colagar, A. H.; Khorshidian, A.; Amini, S. M. The Functional Roles of Curcumin on Astrocytes in Neurodegenerative Diseases. Neuroimmunomodulation 2021, 1-11, https://doi.org/10.1159/000517901.

31. Mohanty, R.; Das, S. K.; Singh, N. R.; Patri, M. Withania somnifera leaf extract ameliorates benzo [a] pyreneinduced behavioral and neuromorphological alterations by improving brain antioxidant status in zebrafish (Danio rerio). Zebrafish 2016, 13, 188-196, https://doi.org/10.1089/zeb.2015.121.

32. Dal Santo, G.; Conterato, G. M.; Barcellos, L. J.; Rosemberg, D. B.; Piato, A. L. Acute restraint stress induces an imbalance in the oxidative status of the zebrafish brain. Neuroscience Letters 2014, 558, 103-108, https://doi.org/10.1016/j.neulet.2013.11.011.

33. Deori, M.; Devi, D.; Kumari, S.; Hazarika, A.; Kalita, H.; Sarma, R.; Devi, R. Antioxidant effect of sericin in brain and peripheral tissues of oxidative stress induced hypercholesterolemic rats. Frontiers in pharmacology 2016, 7, 319, https://doi.org/10.3389/fphar.2016.00319.

34. Ohkawa, H.; Ohishi, N.; Yagi, K. Assay for lipid peroxides in animal tissues by thiobarbituric acid reaction. Analytical biochemistry 1979, 95, 351-358, https://doi.org/10.1016/0003-2697(79)90738-3.

35. Levine, R. L.; Garland, D.; Oliver, C. N.; Amici, A.; Climent, I.; Lenz, A. G.; Stadtman, E. R. Determination of carbonyl content in oxidatively modified proteins. Methods in enzymology 1990, 186, 464-478, https://doi.org/10.1016/0076-6879(90)86141.

36. Ellman, G. L. Tissue sulfhydryl groups. Archives of biochemistry and biophysics 1959, 82, 70-77, https://doi.org/10.1016/0003-9861(59)90090-6.

37. Tietze, F. Enzymic method for quantitative determination of nanogram amounts of total and oxidized glutathione: applications to mammalian blood and other tissues. Analytical biochemistry 1969, 27, 502-522, https://doi.org/10.1016/0003-2697(69)90064-5.

38. Schulz, J. B.; Lindenau, J.; Seyfried, J.; Dichgans, J. Glutathione, oxidative stress and neurodegeneration. European Journal of Biochemistry 2000, 267, 4904-4911, https://doi.org/10.1046/j.14321327.2000.01595.X.

39. Wu, J. Y.; Lin, C. Y.; Lin, T. W.; Ken, C. F.; Wen, Y. D. Curcumin affects development of zebrafish embryo. Biological \& pharmaceutical bulletin 2007, 30, 1336-1339, https://doi.org/10.1248/bpb.30.1336.

40. Erusan, R.; Balasubramanian, M.; Kalyanaraman, S. Raw turmeric and pure curcumin: a comparison of embryonic cytotoxicity in zebrafish. International Journal of Basic \& Clinical Pharmacology 2017, 6, 2020, http://doi.org/10.18203/2319-2003.ijbcp20173290.

41. Alafiatayo, A. A.; Lai, K. S.; Syahida, A.; Mahmood, M.; Shaharuddin, N. A. Phytochemical evaluation, embryotoxicity, and teratogenic effects of Curcuma longa extract on zebrafish (Danio rerio). Evidence-Based Complementary and Alternative Medicine 2019, https://doi.org/10.1155/2019/3807207.

42. Concetta Scuto, M.; Mancuso, C.; Tomasello, B.; Laura Ontario, M.; Cavallaro, A.; Frasca, F.; Calabrese, V. Curcumin, hormesis and the nervous system. Nutrients 2019, 11, 2417, https://doi.org/10.3390/nu11102417.

43. $\mathrm{Hu}, \mathrm{Q}$; Luo, Y. Chitosan-based nanocarriers for encapsulation and delivery of curcumin: A review. International Journal of Biological Macromolecules 2021, https://doi.org/10.1016/j.ijbiomac.2021.02.216.

44. Morshedi, K.; Borran, S.; Ebrahimi, M. S.; Masoud khooy, M. J.; Seyedi, Z. S.; Amiri, A.; Mirzaei, H. Therapeutic effect of curcumin in gastrointestinal cancers: A comprehensive review. Phytotherapy Research 2021, https://doi.org/10.1002/ptr.7119.

45. Pourbagher-Shahri, A. M.; Farkhondeh, T.; Ashrafizadeh, M.; Talebi, M.; Samargahndian, S. Curcumin and cardiovascular diseases: focus on cellular targets and cascades. Biomedicine \& Pharmacotherapy 2021, 136, https://doi.org/10.1016/j.biopha.2020.111214. 
46. Beltzig, L.; Frumkina, A.; Schwarzenbach, C.; Kaina, B. Cytotoxic, Genotoxic and Senolytic Potential of Native and Micellar Curcumin. Nutrients 2021, 13, 2385, https://doi.org/10.3390/nu13072385.

47. Mahjoob, M.; Stochaj, U. Curcumin nanoformulations to combat aging-related diseases. Ageing Research Reviews 2021, 101364, https://doi.org/10.1016/j.arr.2021.101364.

48. Mohseni, M.; Sahebkar, A.; Askari, G.; Johnston, T. P.; Alikiaii, B.; Bagherniya, M. The clinical use of curcumin on neurological disorders: An updated systematic review of clinical trials. Phytotherapy Research 2021, https://doi.org/10.1002/ptr.7273.

49. Meng, R.; Wu, Z.; Xie, Q. T.; Cheng, J. S.; Zhang, B. Preparation and characterization of zein/carboxymethyl dextrin nanoparticles to encapsulate curcumin: Physicochemical stability, antioxidant activity and controlled release properties. Food Chemistry 2021, 340, 127893, https://doi.org/10.1016/j.foodchem.2020.127893.

50. Beyene, A. M.; Moniruzzaman, M.; Karthikeyan, A.; Min, T. Curcumin Nanoformulations with Metal Oxide Nanomaterials for $\quad$ Biomedical Applications. Nanomaterials $\quad \mathbf{2 0 2 1}, 11, \quad 460$, https://doi.org/10.3390/nano11020460.

51. Alagawany, M.; Farag, M. R.; Abdelnour, S. A.; Dawood, M. A.; Elnesr, S. S.; Dhama, K. Curcumin and its different forms: A review on fish nutrition. Aquaculture 2020, 736030, https://doi.org/10.1016/j.aquaculture.2020.736030.

52. Zahedipour, F.; Hosseini, S. A.; Sathyapalan, T.; Majeed, M.; Jamialahmadi, T.; Al-Rasadi, K.; Sahebkar, A. Potential effects of curcumin in the treatment of COVID-19 infection. Phytotherapy Research 2020, 34, 2911-2920, https://doi.org/10.1002/ptr.6738.

53. Manoharan, Y.; Haridas, V.; Vasanthakumar, K. C.; Muthu, S.; Thavoorullah, F. F.; Shetty, P. Curcumin: A wonder drug as a preventive measure for COVID19 management. Indian Journal of Clinical Biochemistry 2020, 35, 373-375, https://doi.org/10.1007/s12291-020-00902-9.

54. Mansouri, K.; Rasoulpoor, S.; Daneshkhah, A.; Abolfathi, S.; Salari, N.; Mohammadi, M.; Shabani, S. Clinical effects of curcumin in enhancing cancer therapy: A systematic review. BMC cancer 2020, 20, 1-11, https://doi.org/10.1186/s12885-020-07256-8.

55. Scazzocchio, B.; Minghetti, L.; D’Archivio, M. Interaction between gut microbiota and curcumin: a new key of understanding for the health effects of curcumin. Nutrients 2020, 12, 2499, https://doi.org/10.3390/nu12092499.

56. Hasanzadeh, S.; Read, M. I.; Bland, A. R.; Majeed, M.; Jamialahmadi, T.; Sahebkar, A. Curcumin: an $\begin{array}{lllll}\text { inflammasome } \quad \text { silencer. } & \text { Pharmacological } & \text { research } & \text { 2020, 159, }\end{array}$ https://doi.org/10.1016/j.phrs.2020.104921.

57. Stohs, S. J.; Chen, O.; Ray, S. D.; Ji, J.; Bucci, L. R.; Preuss, H. G. Highly bioavailable forms of curcumin and promising avenues for curcumin-based research and application: A review. Molecules 2020, 25, 1397, https://doi.org/10.3390/molecules25061397. 